\title{
Летальные отравления в Азербайджане: эпидемиология, факторы риска и возможные пути профилактики
}

\author{
Эфендиев И. Н. ${ }^{1}$, Бунятов М. О. ${ }^{1}$, Ахундова М. Т. ${ }^{2}$ \\ 1 - Азербайджанский Медицинский Университет, г. Баку, Азербайджан \\ 2 - Научно-практическое и Учебное Объединение «Судебная Медииина и Патологическая Анатомия» МЗ, г. \\ Баку, Азербайджан
}

Согласно данных ВОЗ ежегодно около 350.000 человек в мире умирают от острых отравлений химической этиологии [ $\left.{ }^{1}\right]$. Уровень летальности от острых интоксикаций в мире сильно варьирует - от 1$2 \%$ в развитых странах до $15-30 \%$ в некоторых развивающихся государствах. При этом структура фатальных отравлений может сильно меняться от государства к государству, а и даже в пределах различных регионов одной страны $\left[{ }^{1}\right]$.

Некоторыми исследователями отмечено, что несмотря на снижение частотылетальных отравлений у детей, у взрослых отмечается обратная тенденция, в том числе и в развитых странах. $\left[{ }^{1} ;{ }^{1}\right]$. Так, в США за семилетний период 1999-2006 годов уровень летальности от непреднамеренных интоксикаций возрос на $108,5 \% \cdot\left[{ }^{1}\right]$

Целью данной работы было изучение структуры и факторов риска фатальных отравлений в Азербайджане гг. и поиска возможных путей их профилактики.

Ключевые слова: эпидемиология, факторы риска, профилактика

\section{Материалы и методы исследования}

Структура госпитальной летальности от острых отравленийхимической этиологии изучалась по материалам данных клинической базы кафедры внутренних болезней - 1 Азербайджанского

Медицинского

Университета

Республиканского

токсикологического центраза период 2009-2016 гг., которые в свою очередь сравнивались с данными Научно-практическое и Учебное Объединение «Судебная Медицина и Патологическая Анатомия» Министерства Здравоохранения Азербайджанской Республики.

\section{Полученные результаты и их обсуждение}

Сводные данные по структуре госпитальной летальности токсикологического центра обобщены нами втаблице 1.

Обращает на себя внимание, что первое место как в общей структуре госпитальной смертности $(47,7 \%)$, так и по уровню летальности конкретной токсикологической нозологии $(8,38 \%)$ занимали случаи отравлений прижигающими (коррозивными) соединениями, и в частности - концентрированной уксусной кислоты (эссенции).

Доля случаев летальных отравлений уксусной кислотой составили 44,6\% в общей токсико-эпидемиологической структуре фатальных интоксикаций, а смертность данной нозологии достигала рекордных 10,61\%.

Второе место в структуре летальных интоксикаций занимали случаи медикаментозных отравлений - 14,3\%, летальность же данной нозологии была незначительной - $0,82 \%$.

В то же время, среди остальных классификационных рубрик МКБ-10, острые отравления пестицидами (Т60) по уровню летальности находились на втором месте $4,22 \%$. 


\begin{tabular}{|c|c|c|c|c|c|}
\hline НОЗОЛОГИЯ & $\begin{array}{l}\text { Рубрика } \\
\text { МКБ-10 }\end{array}$ & $\begin{array}{c}\text { Всего } \\
\text { больных } \\
\quad \text { (n) }\end{array}$ & $\begin{array}{l}\text { Из них } \\
\text { умерло } \\
\text { (n) }\end{array}$ & $\begin{array}{c}\text { Доля в } \\
\text { структуре } \\
\text { летальности } \\
\text { острых } \\
\text { отравлений - } \\
\text { Т36-Т65 } \\
\text { (\%) }\end{array}$ & $\begin{array}{c}\text { Летальность } \\
\text { нозологии } \\
(\%)\end{array}$ \\
\hline Медикаменты & T36-T50 & 6599 & 54 & 14,3 & 0,82 \\
\hline Наркотики & T40 & 470 & 16 & 4,2 & 3,40 \\
\hline Алкоголь & T51 & 844 & 25 & 6,6 & 2,96 \\
\hline в т.ч. этанол & $T 51.0$ & 830 & 24 & 6,4 & 2,89 \\
\hline в т.ч. суррогаты алкоголя & T51.1 - T51.9 & 14 & 1 & 0,3 & 7,14 \\
\hline $\begin{array}{l}\text { Органические растворители и } \\
\text { нефтепродукты }\end{array}$ & T52 & 729 & 4 & 1,1 & 0,55 \\
\hline в т.ч. растворители & T52.9 & 535 & 4 & 1,1 & 0,75 \\
\hline Прижигающие соединения & T54 & 2148 & 180 & 47,7 & 8,38 \\
\hline в т.ч. уксусная кислота & $T 54.2$ & 1583 & 168 & 44,6 & 10,61 \\
\hline в т.ч. прочие прижигающие & T54.1 - T54.9 & 565 & 12 & 3,2 & 2,12 \\
\hline Угарный газ & T58 & 3628 & 34 & 9,0 & 0,94 \\
\hline Другие токсичные газы & T59 & 61 & 2 & 0,5 & 3,28 \\
\hline Пестициды & T60 & 806 & 34 & 9,0 & 4,22 \\
\hline $\begin{array}{l}\text { в т.ч. фосфорорганическиские } \\
\text { соединения }\end{array}$ & T60.0 & 436 & 22 & 5,8 & 5,05 \\
\hline в т.ч. родентициидьл & $T 60.4$ & 330 & 12 & 3,2 & 3,64 \\
\hline Ядовитые грибы и растения & T62 & 243 & 5 & 1,3 & 2,06 \\
\hline в т.ч. ядовитые грибь & T62.0 & 181 & 5 & 1,3 & 2,76 \\
\hline Животный яд всего & T63 & 921 & 20 & 5,3 & 2,17 \\
\hline в т.ч. яд змей & T63.0 & 676 & 19 & 5,0 & 2,81 \\
\hline в т.ч. яд пауков & T63.3 & 79 & 1 & 0,3 & 1,27 \\
\hline $\begin{array}{l}\text { Прочие и неуточненные } \\
\text { токсические вещества }\end{array}$ & $\begin{array}{l}\text { T53; T56; } \\
\text { T57; T65 }\end{array}$ & 78 & 3 & 0,8 & 3,85 \\
\hline $\begin{array}{l}\text { Синдром Лайела, токсико- } \\
\text { аллергические и пр. побочные } \\
\text { реакции }\end{array}$ & $\begin{array}{l}\text { L51.2; T78.4; } \\
\quad \text { T88.6 }\end{array}$ & 2160 & 13 & - & 0,60 \\
\hline $\begin{array}{l}\text { Всего вещества, } \\
\text { преимущественно } \\
\text { медицинского назначения }\end{array}$ & T36-T50 & 7069 & 70 & 18,6 & 0,99 \\
\hline $\begin{array}{l}\text { Всего вещества, } \\
\text { преимущественно } \\
\text { немедицинского назначения }\end{array}$ & T51-T65 & 9458 & 307 & 81,4 & 3,25 \\
\hline Всего острых отравлений & T36-T65 & 16527 & 377 & 100,0 & 2,28 \\
\hline ВСЕГО & & 18687 & 390 & & 2,09 \\
\hline
\end{tabular}

Таблица 1. Сводные показателей госпитальной токсикологической летальности за 2009-2016 г. 
Нами было также выявлено, что структура фатальных отравлений и уровень летальности по отдельным нозологиям в Азербайджане за последние десятилетия претерпели значительные изменения. Так, летальность от отравлений прижигающими (коррозивными) веществами прогрессивно снижалась на протяжении периода ретроспективных наблюдений и в 2013 году была достоверно $(\mathrm{p}<0,05)$ ниже в сравнении с 1983, 1993 и 2003 годом соответственно.

При рассмотрении уровня летальности в отдельных возрастных

группах токсикологических патологий прослеживалась четкая тенденция к увеличению данного показателя с возрастом. Так, если в возрастной группе 15-19 лет и 20-29 лет процент летальных исходов от острых отравлений составил всего $1,04 \pm 0,22 \%$, то в возрастной группе старше 70 лет данный

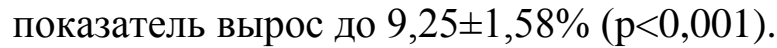

Наибольший процент летальности от острых отравлений химической этиологии наблюдался у мужчин в возрастной группе старше 70 лет (10,7\%), а наименьший $(0,68 \%)$ у мужчин в возрастной группе до 15 лет. У женщин в возрастных группах 20-29 лет; 30-39 и 40-49 лет летальность была достоверно ниже, чем у мужчин $(\mathrm{p}<0,001 ; \mathrm{p}<0,01$ и $\mathrm{p}<0,05$ соответственно).

В структуре летальности от острых отравлений в различных возрастных группах также имелись достоверные отличия.Так, в детской возрастной группе первое ранговое место $\quad(31,25 \pm 8,19 \%) \quad$ занимали медикаментозные отравления, в то время как отравления ядом змей занимали 2-3 место наряду с отравлениями пестицидами (по $15,63 \pm 6,42 \%)$.

В возрастной группе 15-19 лет первое ранговом месте занимали отравления пестицидами $(30,43 \pm 9,59 \%)$, а прижигающие вещества $(17,4 \pm 7,90 \%)$ находились на третьем ранговом месте, уступая интоксикациям монооксидом углерода $(26,09 \pm 9,16 \%)$.

В возрастных группах 20-29, 30-39, 4049, 50-59 60-69 лет среди причин летальных интоксикаций первое ранговое место прочно занимали отравления коррозивами
$(38,33 \pm 6,28 \% ; \quad 42,31 \pm 6,85 \% ; \quad 50,00 \pm 5,98 \%$; $61,90 \pm 5,30 \%$ и $55,26 \pm 8,07 \%$ соответственно). В когорте лиц $\geq 70$ лет доля летальных отравлений прижигающими веществами достигала максимальных значений (64,52 $\pm 8,59 \%)$ среди всех возрастных групп.

Летальные отравления наркотическими веществами встречались в нашем исследовании были зафиксированы только в возрастных группах 15-19; 20-29; 30-39; 40-49 и 50-59 лет.

Имелось достоверное преобладание лиц мужского пола в группах летальных отравлений наркотическими веществами и алкоголем $(\mathrm{p}<0,05)$. В то время как в нозологических группах летальных отравлений, вызванных прижигающими веществами, и в частности уксусной эссенцией, отмечалось достоверное преобладание женщин $(\mathrm{p}<0,05)$. В остальных нозологических когортах (медикаментозные отравления, интоксикации угарным газом, пестициды и пр.) достоверной разницы между гендерными группами зафиксировано не было ( $>>0,05)$.

Было отмечено, что отдельные виды летальных интоксикаций имеют четко выраженный сезонный характер. Так все фатальные интоксикации ядовитыми грибами произошли в осенние месяцы года (сентябрь, октябрь, ноябрь). Степень влияния фактора составил: $С Ф \%=0,09$ (95\% ДИ: 0,05-0,14; $\mathrm{p}<0,001)$. Данное обстоятельство можно непосредственно связать с сезоном активного роста ядовитых грибов, и в первую очередь бледной поганки (Amanita phalloides) в этот период года.

Летальные отравления прижигающими жидкостям достоверно чаще встречались в весенний и летний сезоны. Для весеннего сезона показатель летальности составил $1,19 \pm 0,16 \%$, а летнего для сезона $1,18 \pm 0,16 \%$ соответственно. Степень влияния сезонного фактора оставил СФ\% $=0,05(95 \%$ ДИ: 0,01-0,09; $\mathrm{p}=0,023)$.

Летальные отравления угарным газом преимущественно встречались в холодные месяцы года: зимой показатель данный составил $0,35 \pm 0,08 \%$, весной - 0,24 $\pm 0,07 \%$,

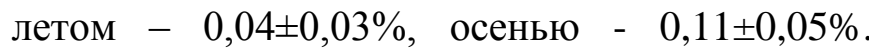
Степень влияния сезонного фактора составил $\mathrm{C} \Phi \%=0,08$ (95\% ДИ: 0,03-0,12; $\mathrm{p}=0,003)$. Все 
летальные случаи отравлений органическими растворителями также приходились на зимнее время года. Степень влияния фактора сезона составил: СФ\% =0,06 (95\% ДИ: 0,02-0,10; $\mathrm{p}=0,014)$.

Летальные отравления ядами животного происхождения в зимнее время года не отмечались. Степень влияния фактора сезона составил: $С Ф \%=0,09$ (95\% ДИ: 0,05-0,14; $\mathrm{p}<0,001)$. Показатель летальности в остальные сезоны составили: весна - 0,13 $\pm 0,05 \%$, лето $0,26 \pm 0,05 \%$, осень - $0,05 \pm 0,03 \%$.

В то же время такие виды отравлений как интоксикации лекарственными средствами, наркотическими веществами, пестицидами и спиртами не имели достоверной связи между летальностью климатическим сезоном года. Сравнительный анализ$$
\text { данा4 }
$$

данных
Токсикологического центра (ТЦ) КТМ с архивными данными Научно-практического и Учебного Объединения Судебной Медицины и Патологической Анатомии МЗ (НУОСМиПА), представленными нами в таблице 2, показал преобладание в структуре летальности НУОСМиПА случаев отравлений угарным газом, отравления же едкими веществами (и в первую очередь - уксусной эссенцией), занимали лишь второе место. Смерть больных с острым отравлением угарным газом, в отличие случаев отравлений уксусной эссенцией, в подавляющем своем большинстве произошла вне стационара, и чаще всего - непосредственно на месте происшествия (несчастного случая).

\begin{tabular}{|c|c|c|c|c|c|c|c|c|c|c|c|c|}
\hline № & Вид отравления & Данные & 2005 & 2006 & 2007 & 2008 & 2009 & 2010 & 2011 & 2012 & 2013 & Всего \\
\hline \multirow[t]{2}{*}{$\mathbf{1}$} & \multirow[t]{2}{*}{ Угарный газ } & НУОСМиПА & 61 & 57 & 78 & 74 & 59 & 100 & 96 & 86 & 59 & 670 \\
\hline & & ТЦ & 2 & 1 & 5 & 4 & 4 & 3 & 5 & 1 & 6 & 31 \\
\hline \multirow[t]{2}{*}{2} & \multirow[t]{2}{*}{ Едкие вещества } & НУОСМиПА & 19 & 14 & 23 & 13 & 20 & 19 & 7 & 6 & 7 & 128 \\
\hline & & ТЦ & 15 & 14 & 15 & 7 & 17 & 17 & 17 & 21 & 9 & 132 \\
\hline
\end{tabular}

\section{Таблица 2. Основные причины летальности от острых отравлений по данным ОСМиПА и ТЦ}

Сравнительный анализ материалов по умершим больным токсикологической нозологии в специализированном стационаре с данными НУОСМиПА МЗ показали, число аутопсий отдельныхнозологических видов острых отравлений в НУОСМиПА превышает число случаев госпитальной летальности данной патологии в токсикологическом центре. В первую очередь это относится к случаям острого токсического воздействия монооксида углерода (угарного газа) и отравлений (передозировками) наркотическими веществами опийного ряда. Данное обстоятельство связано в первую очередь с особенностями действия конкретных групп ксенобиотиков на человеческий организм и скоростью наступления летального исхода отравления, когда смерть пострадавшего наступает в очень краткие сроки, вне стационара и зачастую непосредственно на месте происшествия.
Все случаи летальных отравлений наркотическими веществами в нашем исследовании были представлены интоксикациями кустарными наркотическими веществами опийного ряда (преимущественно героином). Летальных передозировок фармакологическими медикаментозными препаратами наркотического ряда, а также психодислептиками, галлюциногенами, амфетаминами, производными кокаина и др. за период наших проспективных наблюдений отмечено не было.

Полученные данные и их обсуждение.

Госпитальная летальность от острых отравлений в развитых странах Запада составляет около $0,6 \%$ [i] этот показатель составил $2,89 \%$, что во многом обусловливается наличиемспецифической для Азербайджанатоксикологической патологии с высоким уровнем летальности, такой как, например, как отравления уксусной эссенцией, которые не встречаются в Западной Европе и США. 
В нашем проспективном исследовании этанол и суррогаты алкоголяза 8 лет наблюдений стали причиной только $6,6 \%$ случаев всех острых экзотоксикозов, агоспитальная летальность данной патологии составила 2,96\%. В то же время обзор литературы показывает, что вРоссии и многих Европейских странах основной причиной летальных отравлений становился этанол. Так, в Эстонии $\left.{ }^{[i i}\right]$, по результатам 10-летнего анализа проведенных аутопсий этанол стал причиной смерти у $35,1 \%$ всех больных, а отравления наркотическими средствами $20,0 \%$, что значительно превышает полученные нами данные $(6,6 \%$ и 4,2\% соответственно). Обращает также на себя внимание, что в структуре фатальных наркотических отравлений в зарубежных странах на первом месте находились интоксикациизметилфентанилом и фентанилом, веществами, летальных отравлений которыми не было зарегистрировано в Азербайджане за исследуемый период.

Среди фатальных медикаментозных отравлений в Швеции [iii]бензодиазепины, антигистамины и опиоидные анальгетики стали наиболее частыми причинами летальных исходов острых интоксикаций. В Осло (Норвегия) $66 \%$ всех летальных отравлений было обусловлено интоксикациями различными опиатами и опиоидами $\left[{ }^{\mathrm{iv}}\right]$.

В Западной Европе в настоящее время наблюдается тенденция к увеличению летальных отравлений синтетическими наркотиками. Так, в Дании в 2012 году отравления метадоном заняли долю в 59\% в структуре острых интоксикаций, а передозировки героином и морфином сократились до $27 \%{ }^{\mathrm{v}} \mathrm{]}$.

В исследовании, проведенном в Англии и Уэльсе, отмечено увеличение числа смертности от кодеина, трамадола и гаммагидроксибутирата и кетамина $\left[{ }^{\mathrm{vi}}\right]$, а среди летальных отравлений антипсихотическими препаратами первые позиции занимали такие вещества как тиоридазин и хлорпромазин. Отмечено также увеличение числа летальных отравлений атипическими нейролептиками $\left[{ }^{\mathrm{vii}}\right]$.

В нашем исследовании, среди летальных отравлений седативными/психотропными веществами наиболее часто встречались интоксикации

бензодиазипинами,амитриптилином

баклофеном.

Кроме этого, по данным исследований основными причинами догоспитальной летальности от острых отравлений в Европе становились также алкогольные отравления [viii].

В развивающихся странах причиной летальных отравлений наиболее часто становились отравления пестицидами $\left[{ }^{\mathrm{ix}}\right]$. Так, в Шри-Ланке - 77\%, $\left.{ }^{\mathrm{x}}\right]$, а в Непале - 87,2\%

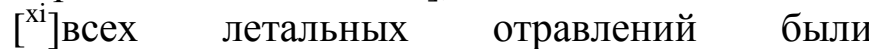
обусловлены приемом пестицидов.

В регионе Чукурова (Çukurova) в соседней, с Азербайджаном странеТурции, за 2007-2011 гг. в структуре острых фатальных отравлений наибольшая доля принадлежала интоксикациям угарным газом (27,0\%), а за ними следовали отравления наркотическими веществами (25\%). В нашем исследовании, доля данных отравлений в общей структуре фатальных интоксикаций составлений составляла соответственно $9,5 \%$ и 4,2\%. Среди отравлений наркотическими веществами, согласно даннымтурецких исследователей наибольшую долю $(69,4 \%)$ занимали опиаты $\left[{ }^{\mathrm{xii}}\right]$, что согласуется также и с нашими данными. В Южных районах Мраморного моря и Восточном Черноморском регионах Турции на первом месте в структуре летальных отравлений находились интоксикации угарным газом - 63,2\% [ $\left.{ }^{\text {xiii }} ;{ }^{x i v}\right]$.

Несмотря на то, что число женщин, госпитализированных с острыми отравлениями превышает число мужчин, среди фатальных интоксикаций коэффициентсоотношения М:Ж в нашем исследовании составил 1,4. В США данный показатель был еще выше и составил 2,4;а в Шри-Ланке - 3,0 $\left.{ }^{\mathrm{xv}}\right]$.Преобладание лиц мужского пола, среди фатальных случаев отравлений было отмечено также в исследованиях, проведенных в Польше [xvi], Эстонии [xvii], Турции [xviii] и других странах.

Во многих странах в структуре фатальных интоксикаций наибольшее число лиц было отмечено в возрастных группах 15-30 лет $\left[{ }^{\mathrm{xix}}\right]$. В Европейском союзе пик летальных отравлений приходился на возрастную группу 
45-49 лет [ $\left.{ }^{\mathrm{xx}}\right]$.

В нашем исследовании в возрастной группе 15-19 лет процент летальных исходов от токсикологической нозологии составил всего $1,04 \pm 0,22 \%$, а возрастной группе старше 70 лет данный показатель достоверно вырос до $9,25 \pm 1,58 \% \quad(\mathrm{p}<0,001)$. Наибольший процент летальности от острых отравлений химической этиологии наблюдался у мужчин в возрастной группе старше 70 лет $(10,7 \%)$, а наименьший $(0,68 \%)$ у мужчин в возрастной группе до 15 лет. Таким образом, исходя из полученных нами результатов,мужчины и лица пожилого возраста находятся под наибольшим риском летального исхода острого экзогенного отравления химической этиологии.

Преднамеренные отравления у молодых были зафиксированы как результат суицидальных попыток и намеренного демонстративного нанесения вреда самому себе, без реального желания умереть (парасуициды).

Как видно из вышесказанного структура летальных отравлений в различных странах мира, и даже в пределах отдельных регионов одной страны, может сильно различаться и зависеть от различных факторов, таких как доступность тех или иных химических веществ, частоты назначаемости определенных медикаментов, социо-экономического положения в обществе, религиозных и культурных факторов и традиций, а также наличия определенной законодательной базы в ракурсе профилактики острых отравлений.

Как было отмечено в нашем исследовании, первое ранговое место средигоспитальной летальности $(44,6 \%)$, а также по уровню смертности среди токсикологических нозологий(10,61\%) занимали отравления уксусной кислотой (эссенций).

Такое значительное число смертельных исходов, обусловленныхприемом именно данного токсиканта, обусловленос одной стороны, причиной его легкодоступности, (свободной продажей и невысокой ценой), а с другой стороны - малой летальной дозой ксенобиотика (всего около 50 мл). Эти обстоятельства сделали данное химическое соединение основной причиной госпитальной летальности от суицидальных интоксикаций в Азербайджане.

Отравления

уксусной кислотой чрезвычайно редко встречаются встранах Западной Европы, поскольку в доступности у населения находится только ее низкоконцентрированные (0,5\%-10\%) растворы. Однако, в некоторых странах Восточной Европы и СНГ, высококонцентрированные растворы уксусной кислоты по-прежнему имеются в свободной продаже, что делает отравления данным химическим соединением значимой причиной смертности от острых интоксикаций. Летальность в группе больных с отравлениями уксусной кислотой достигала по данным разных авторов от 13 до $25 \%$ [xхі;хxii]. Большинство смертельных исходов от отравлений уксусной эссенции наступили в раннем периоде отравления (первые 72 часа), и были связаны с экзотоксическим шоком, выраженным желудочно-кишечным кровотечением, тяжелым внутрисосудистым гемолизом, а также острой токсической почечно-печеночной недостаточностью, что подтверждается также литературными данными [xxiii;xxiv].

Другим видом острых интоксикаций химической этиологии с достаточно серьезным прогнозом течения и исхода заболевания были отравления пестицидами. Во многих развивающихся странах данная патология является ведущей среди летальных отравлений [xxv]. Нами была отмечена неоднородность уровня летальности по данной нозологии в различные годы, что связано с изменением химического состава используемых в сельском хозяйстве и быту различных гербицидов, инсектицидов, родентицидов и других пестицидов, a также более широким использованием широко стали использоваться инсектицидные веществ групп перитроидов и перитринов, практически полностью вытеснивших с рынка пестицидов соединения хлорорганического ряда (ДДТ и пр.).

Таким образом, выявленная нами структура острых летальных отравлений в Азербайджане является по сути уникальной и 
отличается как от стран Западной Европы, где большинство случаев фатальных интоксикаций связано с приемом психотропных веществ,Азии - где преобладают случаи отравлений пестицидами; Финляндии, России и других стран Восточной Европы - где главной причиной летальности от острых отравлений являются алкогольные интоксикации.

Как видно из полученных нами результатов, среди летальных отравлений медикаментознымисредстваминаибольшей

долей были представлены интоксикации седативными/психотропными препаратами и в частности амитриптилином и баклофеном.

Бензодиазепины и барбитураты, являющиеся рецептурными препаратами, в Азербайджане, в настоящее время редко являются причиной летальных отравлений, в сравнении с предыдущими десятилетиями в виду их труднодоступности.

Несмотря на то, что по отдельным видам острых отравлений (угарный газ, наркотические передозировки) большинство летальных исходов происходит вне лечебных учреждений и непосредственно на месте происшествия, летальность данных нозологий является значимой и в специализированном токсикологическом стационаре. При этом,наиболее часто фатальные исходы данными токсикантами в стационаре наблюдались в первые сутки после приема токсиканта. Это еще раз показывает важность как можно более раннего начала адекватного специализированного

лечения

токсикологических больных.

Согласно данным австралийских исследователей $\left[{ }^{\mathrm{xxvi}}\right]$ пациенты $\mathrm{c}$ психиатрическими диагнозами, а также лица, получающие противодиабетические и респираторные препараты, находятся под большим риском фатальных исходов от несуицидальных отравлений.

$66,2 \%$ летальных отравления в нашем исследовании относились к разряду преднамеренных (суицидальных). В исследовании Jha et al., к категории фатальных суицидальных отравлений относились 87,2\% всех случаев [xxvii].В скандинавских странах процент суицидов среди летальных отравлений колебался в пределах 29\%-46\% [ ${ }^{\text {xxviii] }}$.
Как показали наши более ранние исследования $\left[{ }^{\mathrm{xxix}}\right]$ большинство суицидов с применением химических веществбыло связано с наличием постоянного стресса в современной жизни, социально-экономическими проблемами, недопониманием или конфликтами в семье, проблемами в школе и пр. Поэтому важным является разработка программ профилактических мероприятий, направленных на снижение числа суицидальных отравлений.

Превалирование мужчин в нашем исследовании среди случаев фатальных отравлений, связано, по нашему мнению, с тем, что лица мужского пола, более чем женщины имеют склонность к завершенному суициду, последние же чаше совершают попытки парасуицида.

Некоторые действия по профилактикесуицидальныхотравленийдолжны быть приняты и на законодательном уровне. Так, специальная маркировка и безопасная тара для потенциально опасных химических веществ и медикаментов, равно как и их правильное хранение может снизить число летальных отравлений в Азербайджане.

Выявленная нами структура летальности от острых отравлений химической этиологии в Азербайджане может также стать важной отправной точкой для наблюдений за изменениями токсико-эпидемиологической картины фатальных интоксикаций и оценки эффективности проводимых профилактических мероприятий.

\section{Выводы:}

1. В структуре госпитальной летальности от острых отравлений химической этиологии в Азербайджане преобладают случаи интоксикации прижигающими жидкостями $(47,7 \%)$, и в первую очередь, концентрированной уксусной кислотой, летальность отравлениями которой составляла $10,61 \%$.

2. Острые наркотические передозировки и случаи ингаляционных отравлений угарным газом становятся наибольшей причиной летальность непосредственно на месте токсикологического инцидента, в то время как госпитальная летальность 
от данных нозологий была относительно незначительной $\quad 3,40 \%$ и $\quad 0,94 \%$ соответственно.

3. Для снижения частоты фатальных исходов от отравлений угарным газом, помещения, оборудованные газонагревательными и водоотопительными приборами должны быть снабжены детекторами наличия токсичной концентрации моноксида углерода в воздухе.

4. Наличие у линейных бригад высококонкурентного антагониста опийный рецепторов - налоксона при правильном (после интубации ВДП) его применении в адекватных дозах также позволит снизить число летальных исходов отравлений наркотическими веществами на раннем этапе оказания медицинской помощи пострадавшим

Финансовый источник: При написании статьи не использовались финансовые ресурсы.

Конфликт интересов: Нет.

\section{СПИСОК ЛИТЕРАТУРЫ}

1. ${ }^{\text {i } F o r s b e r g ~ S, ~ H o ̈ j e r ~ J, ~ L u d w i g s ~ U . ~ H o s p i t a l ~}$ mortality among poisoned patients presenting unconscious. ClinToxicol (Phila). 2012;50(4):254-7.

2. ${ }^{\mathrm{ii}}$ Tuusov J, Vals $\mathrm{K}$, Tõnisson $\mathrm{M}$, Riikoja A, Denissov G, Väli M. Fatal poisoning in Estonia 2000-2009. Trends in illegal drug-related deaths. J Forensic Leg Med. 2013; 20(1):51-66

3. ${ }^{i i \mathrm{i} J o ̈ n s s o n ~ A K, ~ S p i g s e t ~} \mathrm{O}$, Tjäderborn M, Druid $\mathrm{H}$, Hägg S. Fatal drug poisonings in a Swedish general population. BMC ClinPharmacol. 2009;9:7

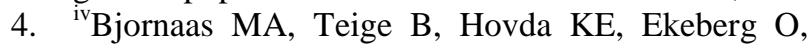
Heyerdahl F, Jacobsen D. Fatal poisonings in Oslo: a one-year observational study. BMC Emerg Med. 2010 Jun 6;10:13

5. ${ }^{\mathrm{v}}$ Simonsen KW, Christoffersen DJ, Banner J, Linnet $\mathrm{K}$, Andersen LV. Fatal poisoning among patients with drug addiction. Dan Med J. 2015 Oct;62(10):A5147.
6. ${ }^{\mathrm{v}}$ Handley SA, Flanagan RJ. Drugs and other chemicals involved in fatal poisoning in England and Wales during 2000 - 2011. ClinToxicol (Phila). 2014; 52(1):1-12.

7. ${ }^{\text {vii Griffiths } \quad \text { C, Flanagan RJ. Fatal }}$ poisoning with antipsychotic drugs, England and Wales 1993-2002. J Psychopharmacol. 2005;19(6):667-774.

8. ${ }^{v i i i}$ Koskela L, Raatiniemi L, Bakke HK, AlaKokko T, Liisanantti J. Do pre-hospital poisoning deaths differ from in-hospital deaths? A retrospective analysis. Scand J Trauma ResuscEmerg Med. 2017 May 8;25(1):48. doi: 10.1186/s13049-017-0391-z.

9. ${ }^{\mathrm{ix}}$ Escoffery CT, Shirley SE. Fatal poisoning in Jamaica: a coroner's autopsy study from the University Hospital of the West Indies. Med Sci Law. 2004; 44(2):116-120.

10. ${ }^{\mathrm{x}}$ Senanayake N, Peiris H. Mortality due to poisoning in a developing agricultural country: trends over 20 years. Hum Exp Toxicol. 1995; 14(10):808-811.

11. ${ }^{\mathrm{xi}} \mathrm{Jda}$ S, Yadav BN. An Analysis of acute fatal poisoning cases coming to mortality of Bpkihs, Dharan. International Journal of Therapeutic Application. 2017; 17: 10-15

12. ${ }^{\text {xil }}$ Battal D, Aktas A, Sungur MA, Bilgin NG, Cekin N. Evaluation of poisoning deaths in the Cukurova Region, Turkey, 2007-2011. Toxicollnd Health. 2016; 32(3): 476-484

13. ${ }^{\text {xiii }}$ Birincioglu I, Karadeniz H, Teke HY. Fatal poisonings in Trabzon (Turkey). J Forensic Sci. 2011;56(3):660-3.

14. ${ }^{\text {xiv }}$ Fedakar R., Turkmen N. Fatal poisonings in the South Marmara region of Turkey, 1996-2003. 2008; $5: 1-8$

15. ${ }^{x v}$ Fingerhut LA, Cox CS. Poisoning mortality. Public Health Report. 1998; 113: 218-233

16. ${ }^{\mathrm{xvi}}$ KrakowiakA, Piekarska-WijatkowskaA, Kobza-SindlewskaK, RogaczewskaA, PolitańskiP, HydzikP, SzkolnickaB, KłopotowskiT, PichetaS, PorębskaB, AntończykA, WaldmanW, SeinAnandJ, MatuszkiewiczE, Łukasik-GłębockaM. PoisoningdeathsinPoland:

TypesandfrequenciesreportedinŁódź, Kraków, Sosnowiec, Gdańsk, WrocławandPoznańduring 2009-2013. Int J Occup Med Environ Health. 2017 Oct 6;30(6):897-908. doi: 10.13075/ijomeh.1896.01063.

17. ${ }^{\mathrm{xvi}}$ Tuusov J, Vals K, Tõnisson M, Riikoja A, Denissov G, Väli M. Fatal poisoning in Estonia 2000-2009. Trends in illegal drug-related deaths. J Forensic Leg Med. 2013 Jan;20(1):51-6. doi: 10.1016/j.jflm.2012.04.023. 
18. ${ }^{\mathrm{xviii}}$ Karaarslan B, Karapirli M, Kandemir E, Kucuker H, Gurler M, Ince CH, Akyol O. The fatal poisoning pattern of Ankara (Turkey) and nearby cities from 2007 to June 2011: a retrospective study in forensic autopsies. J Forensic Sci. 2013 Nov;58(6):1563-7. doi: 10.1111/1556-4029.12189.

19. ${ }^{\mathrm{xix}}$ Kumar S, Pahak A, Mangal HM Trends of Fatal Poisoning In Saurashtra Region of Gujarat. (A Prospective Study). Journal of Indian Academy of Forensic Medicine. 2011 Jul; 33(3): 197-199.

20. ${ }^{x x}$

http://invs.santepubliquefrance.fr/publications/2008/ anamort/poison_related_plaq_anamort_m3_eng.pdf

21. ${ }^{\mathrm{xxi}}$ Grgic D., Hess B. Fatal poisoning by ingestion of $80 \%$ acetic acid // Schweiz Med Forum 2005, V. 5, p. 527-528

22. ${ }^{\text {xxii }}$ Brusin K.M., Krayeva Y.V. Highly Concentrated Acetic Acid Poisoning: 400 Cases Reviewed // Asia Pacific Journal of Medical Toxicology 2012, V. 1, N. 1, p. 3-9

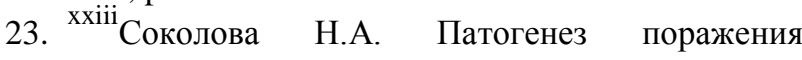
сердечно-сосудистой системы при остром отравлении уксусной кислотой: автореферат дис. ... доктора медицинских наук. Чита. 2012, 42 с.

24. ${ }^{\text {xxiv }}$ Bunyatov M. O. Məhkəmə təbabəti (dərslik). Bakı, "Təbib" nəşriyyati, 2010, 488 c.

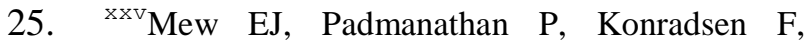
Eddleston M, Chang SS, Phillips MR, Gunnell D. The global burden of fatal self-poisoning with pesticides 2006-15: Systematic review. J Affect Disord. $2017 \quad$ Sep;219:93-104. doi:10.1016/j.jad.2017.05.002.

26. ${ }^{\text {xxvi }}$ Reith DM, Whyte I, Carter G, McPherson M, Carter N. Risk factors for suicide and other deaths following hospital treated self-poisoning in Australia. AustNZJPsychiatry. 2004;38(7):520-525

27. ${ }^{\text {xxvii } J h a ~ S ., ~ Y a d a v ~ B . ~ N ., ~ J h a ~ S . ~ A n ~ a n a l y s i s ~ o f ~ a c u t e ~}$ fatal poisoning cases coming to mortuary of Bpkihs, Dharan. International Journal of Therapeutic Applications, Volume 17, 2014, 10-15

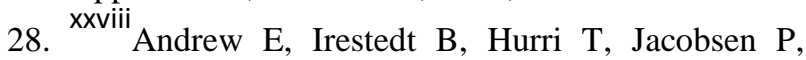
Gidjosdottir G. Mortality and morbidity of poisoning in the Nordic coutries in 2002. ClinicalToxicology. 2008. 46, 310-313

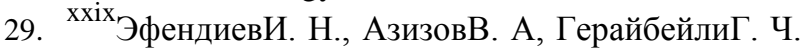
ОтравлениясуицидальногохарактеравАзербайдж ане: результатытрехлетнегопроспективногообсерваци онногоисследования.

AzərbaycanPsixiatriyaJurnal1. 2013, N. 2 (25), c. 1237 